\title{
The differential equation of root movement during its vibration excavation from soil
}

\author{
Bulgakov V. ${ }^{1}$, Adamchuk V. ${ }^{2}$, Holovach I. ${ }^{3}$, Ruzhylo Z. ${ }^{4}$, Ihnatiev Ye. ${ }^{5}$ \\ ${ }^{1,3,4}$ National University of Life and Environmental Sciences of Ukraine \\ 15 Heroiv Oborony Str., Kyiv, 03041, Ukraine \\ ${ }^{2} N S C$ «Institute of Mechanization and Electrification of Agriculture» \\ 11 Vokzalna Str., Hlevakha township, Vasylkiv region, Kyiv oblast, 08631, Ukraine \\ ${ }^{5}$ Tavria State Agrotechnological University named after Dmytro Motornyi \\ 18 B. Khmelnytskyi Ave., Melitopol, Zaporizhzhia oblast, 72312, Ukraine \\ e-mail: 1vbulgakov@meta.ua, ${ }^{2} v$ vadamchuk@gmail.com, ${ }^{3}$ holovach.iv@gmail.com, \\ ruzhylo@nubip.edu.ua, ${ }^{4}$ yevhen.ihnatiev@tsatu.edu.ua \\ ORCID: : $0000-0003-3445-3721,{ }^{2} 0000-0003-0358-7946,{ }^{3} 0000-0003-1387-4789,{ }^{5} 0000-$ \\ 0003-0315-1595
}

Goal. To improve the productivity and quality of digging sugar beetroots by substantiating the rational design and kinematic parameters of the vibrating digging working body. Methods. Theoretical research uses methods of higher mathematics, in particular the integration of differential equations, and theoretical mechanics - the basic law of dynamics of a material point. Results. An equivalent scheme of force interaction of a root with working surfaces of vibrating digging working body is made, on the basis of which a new calculated mathematical model of vibration extraction of beetroot from the soil is constructed. The solution of this system of differential equations on the PC made it possible to build the basic graphical relationships between the structural and kinematic parameters of this process. Conclusions. New analytical dependences of velocity and root movement in time in the direction of translational motion of the vibrating digging working body taking into account its constructive and kinematic parameters are obtained. With the help of PC, the dependences of speed and movement of a root in time at its movement upwards in the course of extraction from soil taking into account constructive and kinematic parameters of the vibrating digging working body are constructed. During the calculations, it was found out that the time of extraction of a root from the soil was $0.032 \mathrm{~s}$.

Key words: sugar beets, plowshare, vibration excavation, working body, force, differential equations, design parameters.

DOI: https://doi.org/10.31073/agrovisnyk202101-06

Recently, the use of vibrating digging tools in sugar beet harvesting machines of modern technical level has become widespread. This is due to their much lower traction resistance, the ability to extract the root crops from the soil virtually without damage and losses. At vibration digging, the stuck soil is intensively shaken from the surface of the root crops, that is, their intensive cleaning occurs even during the extraction from the soil. All this ensures a high quality level of sugar beet harvesting. Thus, scientific research on the process of vibration digging in order to determine the rational design and kinematic parameters of the vibration of digging tools is an urgent task for the sugar beet industry.

Fundamental theoretical and experimental studies of vibratory digging of sugar beet roots were published in [1], in which the root crop is modeled as a body having elastic properties and it is represented by a rod of variable cross-section with one fixed end. The transverse oscillations of the root crop are described in this paper by means of a partial differential equation of the fourth order. The technological process of direct extraction of the root crop from the soil under the vibratory application of forces is practically not considered here, but it is only stated that using additionally composed equations of kinetostatics the conditions of 
its extraction from the soil under the action of the disturbing force applied in the transversevertical plane are found. Here it is considered that exactly this direction of oscillation will be more conducive to quality digging of sugar beet roots.

In [2] the theory of the digging tool of the conventional ploughshare type was developed, where the condition of extraction of root crops from the soil during the forward movement of the digger was found, taking into account the condition of not damaging the root crops. In this work, expressions for determining the allowable speed of forward movement of the digging tool with given its design parameters were obtained.

In [3], the theory of natural and forced longitudinal oscillations of the rootstock in the soil as an elastic body was developed, which is necessary to assess the effect of the specified oscillations on the process of breaking the wilting with the soil.

Features of technological process and tests of modern beet harvesters and their working bodies are covered in a number of foreign scientific researches [4-8]. However, theoretical developments aimed at improving the quality of root crops have not yet yielded comprehensive results. Therefore, scientific research devoted to the substantiation of rational design and kinematic parameters of the vibrating excavating working body, remains relevant today.

The aim of the study. To increase productivity and quality of digging sugar beet roots by substantiating rational design and kinematic parameters of the vibrating digging tool.

Materials and methods of research. The methods of higher mathematics and theoretical mechanics, in particular, the basic law of the dynamics of a material point and the methods of integration of differential equations were used in conducting research.

The results of the study and their analysis. Let's consider the process of digging sugar beet roots with a ploughshare digger, which performs oscillations under the action of vertical harmonic disturbing force, which are transmitted to the ploughshares from the eccentric mechanism of the drive.

To study this process, we made an equivalent scheme of interaction of the root crop with the working surfaces of the vibrating digging working body. For this purpose, let us imagine the vibrating digging tool in the form of two wedges $A_{1} B_{1} C_{1}$ and $A_{2} B_{2} C_{2}$, each of which is inclined in space at angles $\alpha, b, \gamma$ and set so as to form a working channel, the back part of which narrows (Fig. 1). The specified wedges make oscillatory movement in the longitudinalvertical plane, the direction of forward movement of the vibrating excavating working body is shown by an arrow. Let's connect a rectangular Cartesian coordinate system Oxyz to the vibrating excavating working body, center $O$ which is in the middle of the narrowed channel of the excavator, the $O x$ axis coincides with the direction of forward movement of the excavator, the $\mathrm{Oz}$ axis has an upward direction, and the $\mathrm{Oy}$ axis is directed to the right side of the excavator. The projections of points $B_{1}$ and $B_{2}$ on the axis $O y$ denote points $O_{1}$ and $\mathrm{O}_{2}$, respectively.

It is believed that with the wedge surfaces $A_{1} B_{1} C_{1}$ and $A_{2} B_{2} C_{2}$ at the corresponding two points $K_{1}$ and $K_{2}$ there is an interaction of the rootstock, which is approximated by a coneshaped body, is inside the Kopach, whose eigen-axis is parallel to the axis $O z$. Lines drawn through the contact points of the root crop with the wedge planes $A_{1} B_{1} C_{1}$ and $A_{2} B_{2} C_{2}$ and points $B_{1}$ and $B_{2}$, form at the intersection with the sides of the wedges $A_{1} C_{1}$ and $A_{2} C_{2}$ corresponding points $M_{1}$ and $M_{2}$. So $\theta$ - is a dihedral angle $\angle B_{1} M_{1} O_{1}$ between the lower base $A_{1} O_{1} C_{1}$ and the working surface of the wedges $A_{1} B_{1} C_{1}$, or $\angle B_{2} M_{2} O_{2}$ between the lower base $\mathrm{A}_{2} \mathrm{O}_{2} \mathrm{C}_{2}$ and the wedge working surface $\mathrm{A}_{2} B_{2} C_{2}$. 


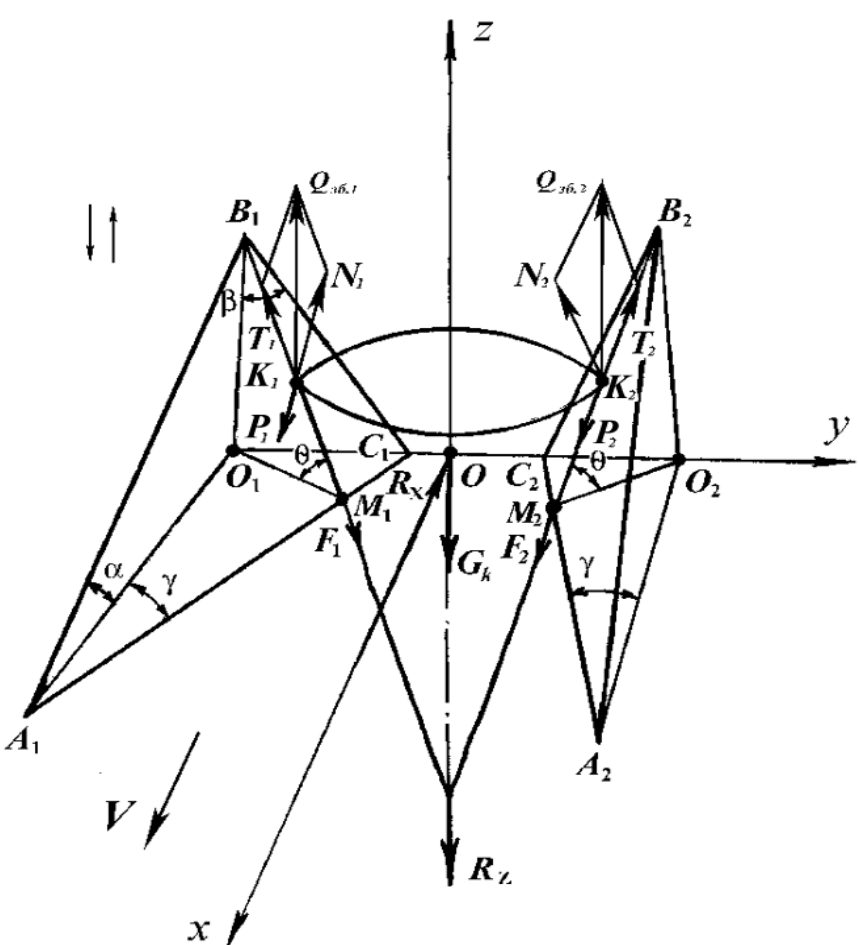

Fig. 1. Force interaction of the beet root with the wedges of the vibrating excavating tool

Let's show the forces resulting from the specified interaction of the root crop with the vibrating digging tool. At the contact points $K_{1}$ and $K_{2}$ of the root crop with the corresponding wedge surfaces $A_{1} B_{1} C_{1}$ and $A_{2} B_{2} C_{2}$ vertical disturbing forces act $\bar{Q}_{\text {зб.1 }}$ and $\bar{Q}_{3 б .2}$, and moreover:

$$
Q_{\text {зб.1 }}=Q_{\text {зб.2 }}=\frac{1}{2} Q_{\text {зб. }}=\frac{1}{2} H \cdot \sin \omega t,
$$

where $H$ - is the amplitude of the disturbing force, $\mathrm{N} ; \omega-$ is the frequency of the disturbing force, $\mathrm{s}^{-1}$.

In addition, at the points of contact $K_{1}$ and $K_{2}$ the driving forces are $\bar{P}_{1}$ and $\bar{P}_{2}$, are directed along the direction of the digger motion (parallel to the Ox axis), and $P_{1}=P_{2}$. As a result of these forces at these points of contact, there are normal reactions $\bar{N}_{1}$ and $\bar{N}_{2}$ on the side of the wedge surfaces $A_{1} B_{1} C_{1}$ and $A_{2} B_{2} C_{2}$ respectively, and $\bar{T}_{1}, \bar{T}_{2}$ - tangential components of disturbing forces $\bar{Q}_{3 б .1}$ and $\bar{Q}_{3 \text { б.2 }}$ respectively. In addition, frictional forces act at these points of contact $\bar{F}_{1}, \bar{F}_{2}$, which arise during the movement of the root crop on the working surfaces of the wedges. Since the vibrating digging tool is the axis of symmetry, we assume that the root crop during its extraction from the ground is located on this axis of symmetry. Also assume that the moduli of paired forces arising on the corresponding planes of wedges are equal to each other. In the center of gravity of the beet the force $\bar{G}-$ the weight of the root crop, its lashing force (adhesion) to the ground is denoted by $\bar{R}_{z}$.

Let us make a differential equation of motion of the beet during its extraction from the soil. In vector form it will have the following form:

$$
m \bar{a}=\bar{N}_{1}+\bar{N}_{2}+\bar{F}_{1}+\bar{F}_{2}+\bar{P}_{1}+\bar{P}_{2}+\bar{R}_{z}+\bar{G}_{k},
$$

where $m$ - mass of the root vegetable; $a$ - acceleration of rootstock extraction from the soil.

It should be noted at once that since the components of normal reactions $N_{i}$ working surfaces $A_{1} B_{1} C_{1}$ and $A_{2} B_{2} C_{2}$ to the $O y$ axis are equal in magnitude and oppositely directed, then the removal of the root crop from the soil occurs actually only in the plane 
$x O z$, and therefore the vector equation (2) is reduced to a system of two equations in projections to the Cartesian coordinate system axes:

$$
\left.\begin{array}{l}
m \ddot{x}=N_{1 x}+N_{2 x}+F_{1 x}+F_{2 x}+P_{1 x}+P_{2 x}-R_{x}, \\
m \ddot{z}=N_{1 z}+N_{2 z}-F_{1 z}-F_{2 z}-R_{z}-G_{k} .
\end{array}\right\}
$$

By determining the value of all forces included in equation (2) and the projections of these forces included in the system of equations (3), we obtain the following system of differential equations:

$$
\begin{aligned}
& m \ddot{x}=H \cos \theta \sin \theta \sin \gamma \sin \omega t+f H \cos ^{2} \theta \sin \gamma \sin \omega t+2 P_{1}-R_{x}, \\
& m \ddot{z}=H \cos ^{2} \theta \sin \omega t-f H \cos \theta \sin \theta \sin \omega t-R_{z}-G_{k} .
\end{aligned}
$$

The resulting system of differential equations describes the process of vibration removal of the root crop from the soil along the coordinate axes, that is, its movement to complete removal.

Let us integrate this system of differential equations, thus determining the velocity and law of motion of the root crop along the coordinate axes. To do this, write differential equation (5) in the following form:

$$
\ddot{z}=\frac{H}{m}\left(\cos ^{2} \theta-f \cos \theta \sin \theta\right) \cdot \sin \omega t-\frac{R_{Z}}{m}-\frac{G_{k}}{m} .
$$

If we reintegrate this differential equation twice, we obtain the value of velocity and displacement of the root crop in the direction of the $\mathrm{Oz}$ axis as a function of time.

The first integral will be equal:

$\dot{z}=-\frac{H}{m \omega}\left(\cos ^{2} \theta-f \cos \theta \sin \theta\right) \cdot \cos \omega t-\frac{1}{m}\left(R_{z}+G_{k}\right) t+C_{1},(7)$

the second integral will be equal to:

$z=-\frac{H}{m \omega^{2}}\left(\cos ^{2} \theta-f \cos \theta \sin \theta\right) \cdot \sin \omega t-\frac{1}{m}\left(R_{z}+G_{k}\right) \frac{t^{2}}{2}+C_{1} t+C_{2}$,

where $C_{1}$ and $C_{2}$ - arbitrary steels.

To determine the arbitrary constants it is necessary to set the initial conditions. At $t=0$ : $z=-h_{1}, \dot{z}=0$,

where $h_{1}$ - the depth of location (fixation) of the root crop in the soil.

Given the initial conditions, we obtain the value of arbitrary constants:

$$
\begin{gathered}
C_{1}=\frac{H}{m \omega}\left(\cos ^{2} \theta-f \cos \theta \sin \theta\right), \\
C_{2}=-h_{1} .
\end{gathered}
$$

After substituting (9) into expressions (7) and (8) we obtain:

$$
\begin{aligned}
& \dot{z}=-\frac{H}{m \omega}\left(\cos ^{2} \theta-f \cos \theta \sin \theta\right) \times \\
& \times \cos \omega t-\frac{1}{m}\left(R_{z}+G_{k}\right) t+ \\
& +\frac{H}{m \omega}\left(\cos ^{2} \theta-f \cos \theta \sin \theta\right), \\
& z=-\frac{H}{m \omega^{2}}\left(\cos ^{2} \theta-f \cos \theta \sin \theta\right) \times \\
& \times \sin \omega t-\frac{1}{m}\left(R_{z}+G_{k}\right) \frac{t^{2}}{2}+\frac{H}{m \omega} \times \\
& \times\left(\cos ^{2} \theta-f \cos \theta \sin \theta\right) t-h_{1} .
\end{aligned}
$$

Thus, the obtained expressions for determining the velocity and displacement of the body in the process of its extraction from the ground along the $\mathrm{Oz}$ axis under given initial conditions. 
From equation (11) we can determine the time $t_{1}$ removal of the root crop from the soil. For this purpose it is necessary to substitute in the left part of equation (11) the value of $z=0$ and solve the resulting equation with respect to $t_{1}$.

Since this equation is transcendental, obtain an analytical expression to determine $t_{1}$ is impossible, but it can be solved on a PC using known numerical methods. The value is calculated $t_{1}$ can be used to determine the productivity of the unit when digging root crops with vibrating digging tools.

Similarly, after twofold integration of the differential equation (4), we can determine the speed and movement of the root crop along the $O x$ axis, i.e. in the direction of forward movement of the vibrating digging tool. To do this, write the differential equation (4) in the following form:

$$
\ddot{x}=\frac{H}{m} \cdot \sin \gamma \cdot\left(\cos \theta \sin \theta+f \cos ^{2} \theta\right) \cdot \sin \omega t+\frac{2 P_{1}-R_{x}}{m} .
$$

Let us integrate this equation twice. After the first integration of the differential equation (12) we obtain:

$$
\dot{x}=-\frac{H}{m \omega} \sin \gamma\left(\cos \theta \sin \theta+f \cos ^{2} \theta\right) \cdot \cos \omega t+\frac{\left(2 P_{1}-R_{x}\right)}{m} \cdot t+L_{1},
$$

after the second integration of the differential equation (12) we have:

where $L_{1}$ and $L_{2}$ - arbitrary steels.

$$
\begin{aligned}
x=- & \frac{H}{m \omega^{2}} \sin \gamma\left(\cos \theta \sin \theta+f \cos ^{2} \theta\right) \cdot \sin \omega t+ \\
& +\frac{\left(2 P_{1}-R_{x}\right)}{m} \cdot \frac{t^{2}}{2}+L_{1} t+L_{2},
\end{aligned}
$$

To determine the arbitrary constants $L_{1}$ and $L_{2}$ it is necessary to set the initial conditions. Thus, at $t=0$ :

$\dot{x}=0, x=x_{o}$,

where $x_{o}$ - is the distance of the vertical axis of the root crop from the origin of the coordinate system (point $O$ ) at the time $t=0$.

Given the initial conditions, we obtain the following results for the value of arbitrary constants:

$L_{1}=\frac{H}{m \cdot \omega} \sin \gamma\left(\cos \theta \cdot \sin \theta+f \cos ^{2} \theta\right)(15)$

and

$$
L_{2}=x_{o}
$$

Let's substitute the obtained values of arbitrary constants $L_{1}$ and $L_{2}$ into expressions (13) and (14), we obtain:

$$
\begin{aligned}
& \dot{x}=-\frac{H}{m \omega} \sin \gamma(\cos \theta \sin \theta+ \\
& \left.+f \cos ^{2} \theta\right) \cos \omega t-\frac{R_{x}}{m} t+ \\
& +\frac{H}{m \omega} \sin \gamma\left(\cos \theta \sin \theta+f \cos ^{2} \theta\right),
\end{aligned}
$$

and

$$
\begin{aligned}
& x=-\frac{H}{m \omega^{2}} \sin \gamma(\cos \theta \sin \theta+ \\
& \left.+f \cos ^{2} \theta\right) \sin \omega t-\frac{R_{x}}{2 m} t^{2}+ \\
& +\frac{H}{m \omega} \sin \gamma(\cos \theta \sin \theta+ \\
& \left.+f \cos ^{2} \theta\right) t+x_{o} .
\end{aligned}
$$


So, the obtained values of the velocity and displacement projections of the rootstock on the $O x$ axis as functions of time $t$, satisfying the given initial conditions.

On the basis of the obtained expressions (11) and (18) numerical calculations on a PC in the software environment MathCAD at the specific parameters included in expressions (11) and (18).

To carry out the calculations, we set the value of the parameters necessary for this. These values are chosen according to [9-10].

eight of the root $m_{k}=0,9 \mathrm{~kg}$;

oot length: $h_{k}=0,25 \mathrm{~m}$;

ngles of the triangular wedges of the vibrating excavator: $\gamma=14^{\circ}, \beta=52^{\circ}$;

$-$

oefficient of friction of steel on the surface of the rootstock: $f=0,45$;

oil resistance forces when moving the root crop: $R_{x}=100 \mathrm{H}, R_{z}=100 \mathrm{~N}$;

mplitude of the disturbing force: $H=500 \mathrm{~N}$;

ateral driving force value: $P_{1}=400 \mathrm{~N}$;

сходное положение центра масс корнеплода по оси $O_{1} x_{1}: x_{10}=0,2 \mathrm{~m}$.

Calculations will be made for the vibration frequency of the vibrating digging tool $v=10 \mathrm{~Hz}$.

Based on the obtained law of motion of the center of mass of the root crop (11) and (18) in the coordinate system $x O z$ let's build in an environment MathCAD graphics $x=x(t), z=$ $z(t)$ (Fig. 2) in order to determine the time of extraction of root crops from the soil during vibration digging.

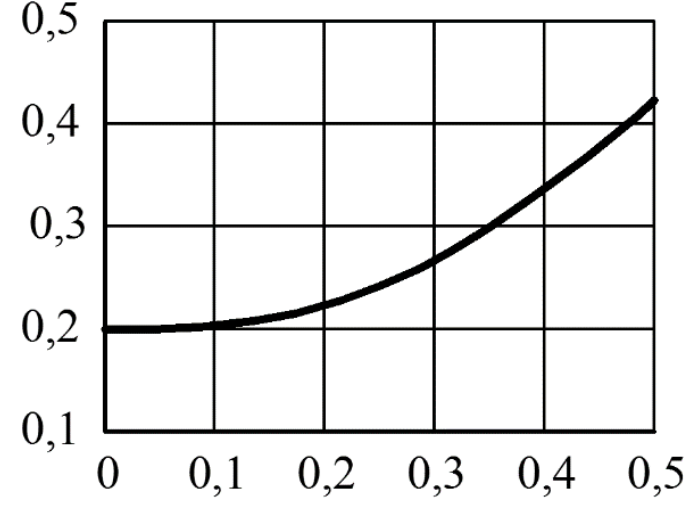

a

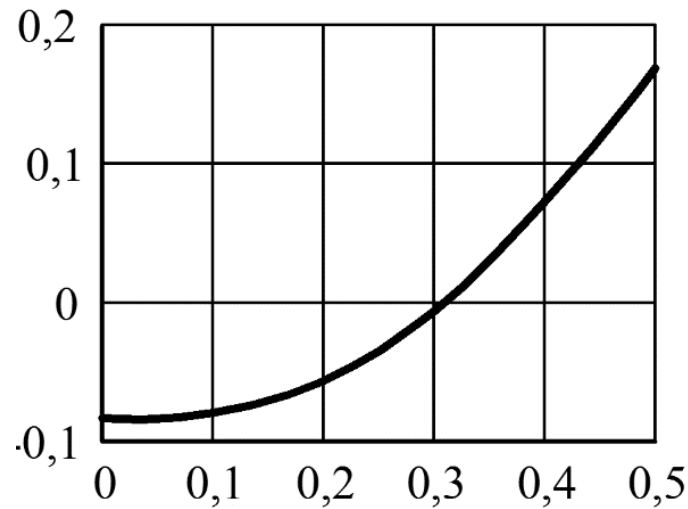

$b$

Fig. 2. Plots of dependencies of the center of mass movement of the root crop along the axes $O x$ (a) and $O z$ (b) from the time of direct removal of the root crop from the soil $\left(H=500 \mathrm{~N}, P_{1}=400 \mathrm{~N}, R_{x}=100 \mathrm{~N}, R_{z}=100 \mathrm{~N}, v=10 \mathrm{~Hz}\right.$ )

As can be seen from the graph, the time of extraction of the root crop from the soil $(z=$ $0)$ is $0.032 \mathrm{~s}$. 
Also calculations of the displacement of the center of mass of the root crop along the $\mathrm{Oz}$ axis until complete removal depending on changes in the amplitude of the perturbing force and the resulting graphs $z=z(H, t)$ at $P_{1}=$ const, and $z=z\left(P_{1}, t\right)$ at $H=$ const.

Fig. 3. shows the surface and the contour plot of the function $z=z(H, t)$ when varying the amplitude of the disturbing force in the range $H=100 \ldots 700 \mathrm{~N}$ (for lateral driving force $P_{1}=400 \mathrm{~N}$ and oscillation frequency $v=10 \mathrm{~Hz}$ ).

As can be seen from the above graph, if the amplitude of the disturbing force varies within $100 \ldots 700 \mathrm{H}$, the extraction of the root crop from the soil varies in the range $0.053 \ldots 0,028 \mathrm{~s}$.

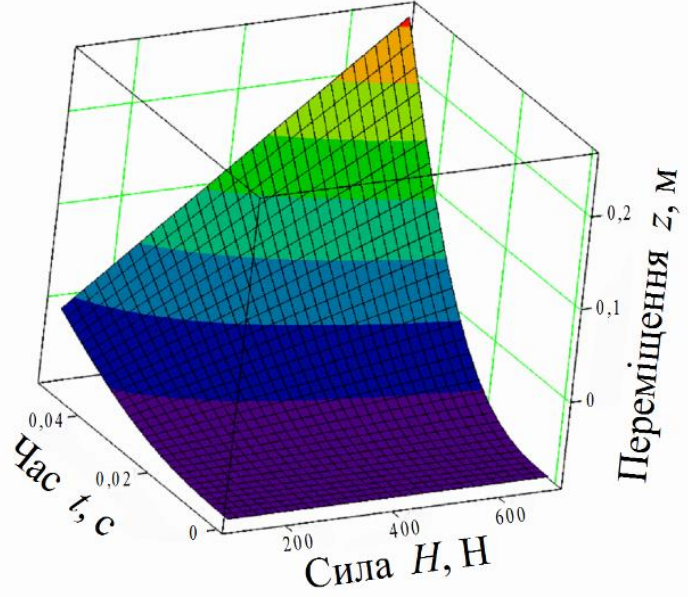

a

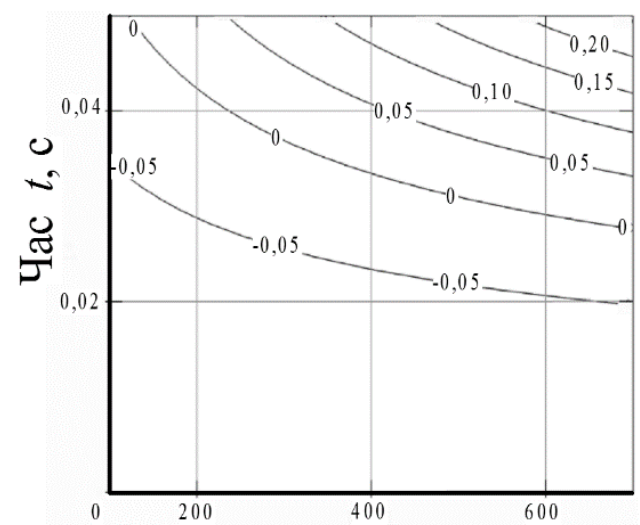

Сила $H, \mathrm{H}$

$\mathrm{b}$

Fig. 3. Surface (a) and contour plot (b) of the function $z=z(H, t)$ when the disturbing force amplitude changes in the range $H=100 \ldots 700 \mathrm{~N}\left(P_{1}=400 \mathrm{~N}\right.$, $v=10 \mathrm{~Hz}$ )

Fig. 4 shows the surface and the contour plot of the function $z=z\left(P_{1}, t\right)$ when changing the lateral driving force in the range $P_{1}=100 \ldots 700 \mathrm{~N}$ (for values of the amplitude of the disturbing force $H=500 \mathrm{~N}$ and oscillation frequency $v=10 \mathrm{~Hz}$ ).

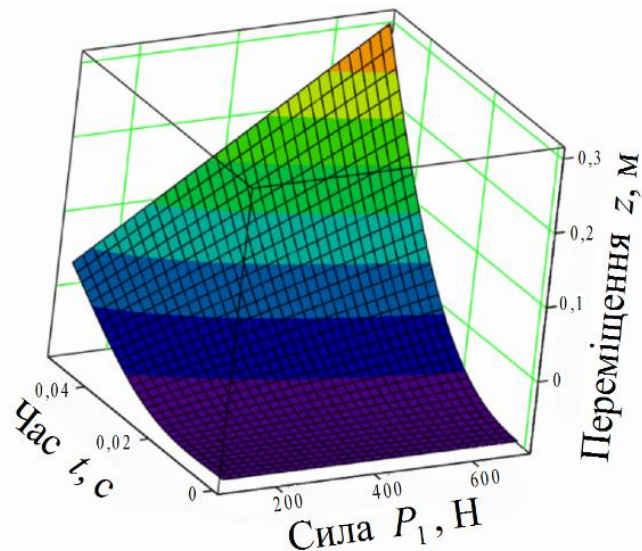

a

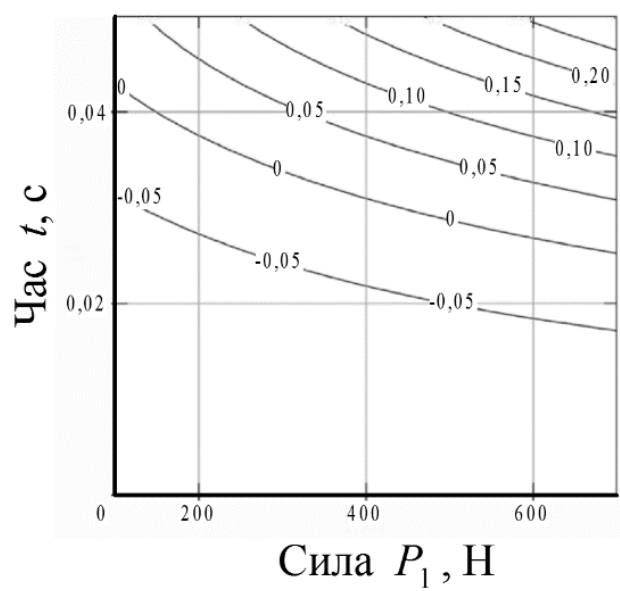

b

Fig. 4. Surface (a) and contour plot (b) of the function $z=z\left(P_{1}, t\right)$ when changing the lateral driving force in the range $P_{1}=100 \ldots 700 \mathrm{~N}(\mathrm{H}=500 \mathrm{~N}, v=10 \mathrm{~Hz})$

As can be seen from the graph above, if the lateral driving force changes within $100 \ldots 700 \mathrm{~N}$ of the extraction of the root crop from the soil varies within the range of 
$0,043 \ldots 0,026 \mathrm{~s}$.

Taking into account the results of the study, we have developed new designs of vibrating digging tools [11-13], the use of which improves the quality of this technological process.

\section{Conclusions}

A new computational mathematical model of vibration extraction of beet roots from the soil is constructed.

Constructed dependences of speed and movement of the root crop in time in the direction of forward movement of vibrating excavating working body taking into account its design and kinematic parameters.

Constructed dependences of speed and movement of the root crop in time during its movement upwards in the process of extraction from the soil, taking into account the design and kinematic parameters of the vibrating vibropuvial working body.

During the calculations, it was found that the extraction of the root crop from the soil is equal to $0.032 \mathrm{~s}$.

\section{References}

1. Vasylenko, P.M., Pohorilyi, L.V., \& Brei, V.V. (1970). Vibratsiinyi sposib zbyrannia koreneplodiv [Vibrating method of harvesting roots]. Mechanization and the electrification of the socialist Agriculture, 2, 9 - 13. [In Ukrainian].

2. Bulhakov, V.M., \& Holovach, I.V. (2002). Utochnena teoriia vykopuiuchoho robochoho orhana lemishnoho typu [Refined theory excavating working body of the ploughshare type]. Bulletin of Agrarian Science of the Black Sea Coast, 4 (18). T I. Mykolaiv: MDAU, 37 - 63. [In Ukrainian].

3. Bulhakov, V.M., \& Holovach, I.V. (2003). Matematychne modeliuvannia pozdovzhnikh kolyvan koreneplodu pry vibratsiinomu vyluchenni z gruntu [Mathematical modeling of longitudinal oscillations of the root crop when vibrating removal from the soil]. Vibration in engineering and technology, 1 (27), 11 - 14. [In Ukrainian].

4. Boson, E.S., Verniaev, O.V., Smirnov, I.I. \& Sultan-Shach E.G. (2019). Theory, Construction and Calculation of Agricultural Machines. 2nd Ed., Scientific Publisher.

5. Gu, F., Hu, Z., Wu, H. et al. (2014). Development and experiment of 4LT-A staggereddig sugar beet combine. Nongye Gongcheng Xuebao. Transactions of the Chinese Society of Agricultural Engineering, 30(23), 1 - 9.

6. Schmitz, T.L., \& Smith, K.S. (2012). Mechanical vibrations: Modeling and measurement. Springer. doi: 10.1007/978-1-4614-0460-6

7. Schulze Lammers P. Harvest and loading chines for sugar beet - new trends. 2011. International Sugar Journal, 113 (1348), 253 - 256.

8. Schulze Lammers, P.S. \& Schmittmann, O. (2013). Testing of sugar beet harvesters in Germany 2012. International Sugar Journal, 115(1370), 100 - 106.

9. L.V. Pogorelyy, N.V. Tatyanko, V.V. Brey et al. (Pogorelyi L.V. (Ed.)). (1983). Sveklouborochnye mashiny (konstruirovanie i raschet). Kiev: Tekhnika. [In Russian].

10. Bulhakov, V.M., \& Holovach, I.V. (2003). Teoriia vibratsiinoho vykopuvannia koreneplodiv [The theory of vibration tional digging of roots]. Coll. Science National Agrarian University "Mechanical organization of agricultural production", XIV, 34 - 86. [In Ukrainian].

11. Bulhakov V.M., Zykov P.lu., Tsurpal I.A., Finko S.V., \& Savchenko A.M. (1996). Pat. № 9709 Ukrainy. Vibrokopach dlia koreneplodiv, opubl. v biul. № 3 [Pat. № 9709 of Ukraine. Vibrator for root crops, publ. in the bull. № 3]. [In Ukrainian].

12. Bulhakov V.M., Zykov P.Iu., Tsurpal I.A., Finko S.V., \& Savchenko A.M. (1996). Pat. № 10723 Ukrainy. Vibrokopach dlia koreneplodiv, opubl. v biul. №4 [Pat. № 10723 of Ukraine. Vibrator for root crops, publ. in the bull. №4]. [In Ukrainian].

13. Bulhakov V.M., Zykov P.lu., Tsurpal I.A., Finko S.V., \& Savchenko A.M. (1996). Pat. № 10724 Ukrainy. Vibrokopach dlia koreneplodiv, opubl. v biul. №4 [Pat. № 10724 of Ukraine. Vibrator for root crops, publ. in the bull. №4]. [In Ukrainian]. 